\title{
Oxygen free radical damage in the cornea after excimer laser therapy
}

\author{
Seiji Hayashi, Sei-ichi Ishimoto, Guey-Shuang Wu, Won R Wee, Narsing A Rao, \\ Peter J McDonnell
}

\begin{abstract}
Aims/background-To evaluate the extent of oxygen radical damage in the cornea after excimer laser ablation.

Methods-The $193 \mathrm{~nm}$ argon fluoride excimer laser was programmed for an average fluence of $150 \mathrm{~mJ} / \mathrm{cm}^{2}$, with a firing rate of $5 \mathrm{~Hz}$ and an ablation zone diameter of $6 \mathrm{~mm}$. Phototherapeutic keratectomy was performed to remove $30 \mu \mathrm{m}$ of epithelium and $50 \mu \mathrm{m}$ of stroma from the corneas of New Zealand white rabbits. Oxidative tissue damage after laser was determined by measuring oxidised lipids (conjugated dienes and ketodienes) in corneal lipid extracts, and by fast blue $B$ staining to localise the lipid peroxide in the tissue.
\end{abstract}

Results-Conjugated diene levels were 3.73 (SD 0.56) nmol per hemicornea in ablated corneas and $1.99(0.33)$ nmol per hemicornea in normal corneas $(\mathbf{p}=$ $0.0044)$. Ketodiene levels were $2.72(0.38)$ nmol per hemicornea in treated corneas and $0.91(0.12)$ nmol per hemicornea in normal corneas $(p<0.001)$. Fast blue $B$ staining disclosed that the tissue damage occurred primarily on the surface of the ablated cornea.

Conclusion-The presence of lipid peroxidation in the superficial corneal stroma in excimer laser treated corneas was demonstrated. This lipid peroxidation could be from oxygen free radicals generated by the infiltrating polymorphonuclear cells at the site of tissue damage.

(Br F Ophthalmol 1997;81:141-144)

The efficacy of the $193 \mathrm{~nm}$ excimer laser in treating myopia, astigmatism, and corneal opacities has been established by previous studies. ${ }^{1-5}$ As laser therapy has advanced, efforts have been made to elucidate the pathological and microstructural changes that are present after photorefractive keratectomy and the effects these changes have on the remaining corneal tissue. Studies have shown that the ablated surface of the cornea undergoes several biochemical reactions such as the deposition of laminin, fibrinogen, and fibronectin. ${ }^{6}$ Follow- ing excimer laser treatment, the local inflammatory responses include infiltration of the corneal stroma by polymorphonuclear cells (PMNs) and production of inflammatory mediators such as prostaglandin E2 and leukotriene $\mathrm{B} 4$.

Superoxide and other reactive oxygen metabolites are potent inflammatory mediators produced by activated PMNs that are recruited to the site of inflammation. As the PMNs are activated by the nicotinamide adenine diphosphate hydrogen (NADPH) and the respiratory burst oxidase, $\mathrm{O}_{2}^{-}$is generated by these phagocytes. The $\mathrm{O}_{2}^{-}$dismutates to $\mathrm{H}_{2} \mathrm{O}_{2}$ and accelerates the metal ion dependent formation of highly reactive $\mathrm{OH}^{-}$from $\mathrm{H}_{2} \mathrm{O}_{2} \cdot{ }^{89}$ These proinflammatory agents can damage the surrounding healthy tissues by peroxidation of lipid membranes and by induction of alterations in cellular proteins and other molecules. ${ }^{111}$

The purpose of this study was to evaluate the extent of lipid peroxidation in the cornea after excimer laser ablation.

\section{Material and methods}

EXPERIMENTAL ANIMALS

Seven New Zealand white male rabbits weighing $2.5 \mathrm{~kg}$ were anaesthetised with intramuscular injections of ketamine hydrochloride and xylazine. After induction of anaesthesia, topical proxymetacaine (proparacaine) was applied to the rabbits corneas and the $193 \mathrm{~nm}$ argon fluoride excimer laser (Twenty-Twenty Excimer Laser, Visx Inc, Sunnyvale, CA, USA) was used to treat both eyes as has been described previously. ${ }^{7}$ Briefly, the laser was programmed for an average fluence of $150 \mathrm{~mJ} / \mathrm{cm}^{2}$ with a firing rate of $5 \mathrm{~Hz}$ and an ablation zone diameter of $6 \mathrm{~mm}$. In the first step $30 \mu \mathrm{m}$ of epithelium was removed by laser ablation; thereafter, phototherapeutic keratectomy was performed on the corneal stroma to a depth of $50 \mu \mathrm{m}$. Ten rabbits that were not treated were used as controls. All treated animals were killed by intravenous injection of pentobarbitone 24 hours after treatment and the eyes were enucleated. Control animals were killed under the same conditions as the treated rabbits and the eyes were also enucleated. All procedures used were in full accord with the Association
Accepted for publication 14 October 1996 


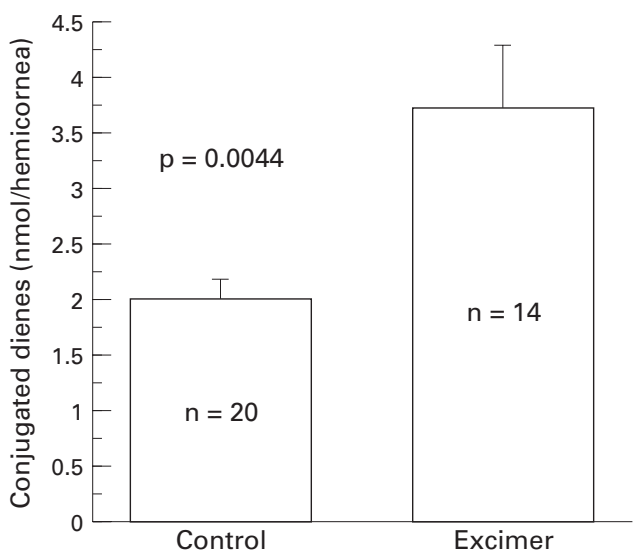

Figure 1 Rabbit corneas were subjected to excimer laser keratectomy with an average fluence of $150 \mathrm{mf} / \mathrm{cm}^{2}$, a firing rate of $5 \mathrm{~Hz}$ and an ablation zone diameter of $6 \mathrm{~mm}$. Conjugated dienes were measured in lipid extracts of the rabbit corneas 24 hours after excimer laser keratectomy. Control corneas were not treated.

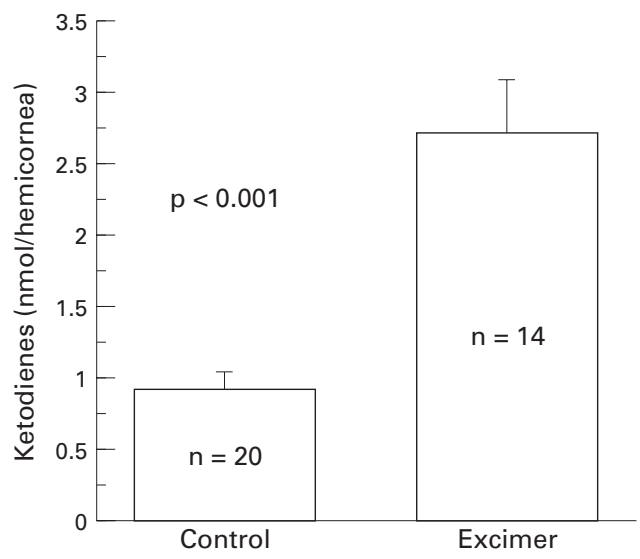

Figure 2 Rabbit corneas were subjected to excimer laser keratectomy with an average fluence of $150 \mathrm{mf} / \mathrm{cm}^{2}$, a firing rate of $5 \mathrm{~Hz}$ and an ablation zone diameter of $6 \mathrm{~mm}$. Conjugated ketodienes were measured in lipid extracts of the rabbit corneas 24 hours after excimer laser keratectomy. Control corneas were not treated.

for Research in Vision and Ophthalmology Resolution on the Use of Animals in Research.

DETERMINATION OF TISSUE DAMAGE BY REACTIVE OXYGEN METABOLITES

The corneas were trephined from the globes of both eyes of each rabbit using a $7.5 \mathrm{~mm}$ Barron-Hessburg vacuum trephine (Jedmed Instrument Co, St Louis, MO, USA). One half of each cornea was immediately snap frozen in OCT compound for histology. The other half of each cornea was used for evaluation of tissue lipid peroxidation. In numbers, it represented 14 hemicorneas from treated animals and 20 hemicorneas from normal animals that were used for conjugated diene and ketodiene measurements; the other portions of hemicorneas from each group were used for histological studies.

The method for measuring conjugated dienes and ketodienes in the tissue has been described previously. ${ }^{12}$ The total lipids were extracted by the method of Folch et al. ${ }^{13}$ For each determination, half of a cornea button from each eye was homogenised and extracted with $1 \mathrm{ml}$ of chloroform/methanol (2:1). The extract was washed with $0.2 \mathrm{ml}$ of distilled water and centrifuged. Solvents were evaporated from the organic layer and the residue was dissolved in $1 \mathrm{ml}$ of anhydrous ethanol (J T Baker Chemical Co, Phillipsburg, NJ, USA) for ultraviolet absorption measurement. A Shimadzu spectrophotometer, model UV-160, was used to record the absorption range of 200-400 nm. Absorbance of $233 \mathrm{~nm}$ was used to measure conjugated dienes, and a molar extinction coefficient of 25200 was used to calculate the quantity of conjugated dienes produced in moles. Absorbance of $280 \mathrm{~nm}$ was used to measure ketodienes with the extinction coefficient of $20000 .^{14}$

\section{HISTOCHEMICAL LOCALISATION OF PEROXIDISED} LIPIDS

Frozen sections were fixed in 5\% trichloroacetic acid for 1 minute, then rinsed in saline $(4 \times$ 5 minutes). The sections were allowed to react overnight at room temperature in a $0.1 \%(\mathrm{w} / \mathrm{v})$ 3-hydroxy-2-naphthoic acid hydrazide (NAH) solution in saline containing $10 \%(\mathrm{v} / \mathrm{v})$ dimethyl sulphoxide (DMSO) and $0.095 \%(\mathrm{w} / \mathrm{v})$ para-toluene sulphonic acid (pTSA) as a catalyst. Sections were then washed $(4 \times 5$ minutes) in a $15 \%(\mathrm{v} / \mathrm{v})$ DMSO solution in $1 \mathrm{mM} \mathrm{HCl}$, and exposed for 20 minutes to a $0.1 \%(\mathrm{w} / \mathrm{v})$ fast blue B (Aldrich Chemical Co, Milwaukee, WI, USA) solution in $0.1 \mathrm{M}$ phosphate buffer, $\mathrm{pH}$ 6.5. ${ }^{15}$ After fast blue B coupling, sections were washed in running tap water for 5 minutes, then in saline for 5 minutes, before embedding in glycerol gelatin.

\section{HISTOPATHOLOGICAL EVALUATION}

To evaluate the presence of PMN infiltration, formalin fixed hemicorneas from treated rabbits and normal controls were embedded in paraffin, and histological sections of $5 \mu \mathrm{m}$ were cut. The sections were stained with haematoxylin and eosin.

\section{STATISTICAL ANALYSIS}

The unpaired two tailed Student's $t$ test was used to evaluate differences between groups.

\section{Results}

Oxygen free radical induced tissue damage was demonstrated by measurement of conjugated dienes and ketodienes from each of the 14 hemicorneas 24 hours after treatment. Our results showed an increased level of lipid peroxidation in laser ablated corneas compared with the 20 non-treated control hemicorneas, as illustrated in Figures 1 and 2, respectively. Conjugated diene measurement showed an increase of $87 \%$ in the treated corneas (3.73 (SD 0.56) nmol per hemicornea) when compared with untreated corneas (1.99 (0.33) nmol per hemicornea). Ketodiene levels were increased by $198 \%$ in the corneas of treated animals $(2.72(0.38) \mathrm{nmol}$ per hemicornea) compared with controls (0.91 (0.12) nmol per hemicornea). Conjugated diene and ketodiene measurements performed in rabbits immediately after excimer laser ablation did 


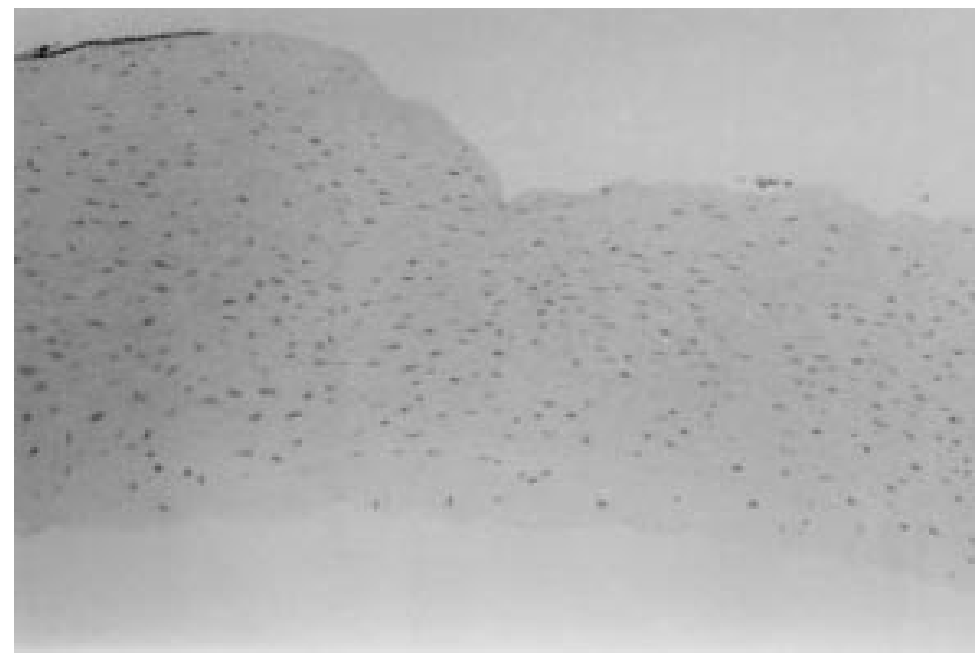

Figure 3 Haematoxylin and eosin staining of an excimer laser ablated cornea removed immediately after the treatment.

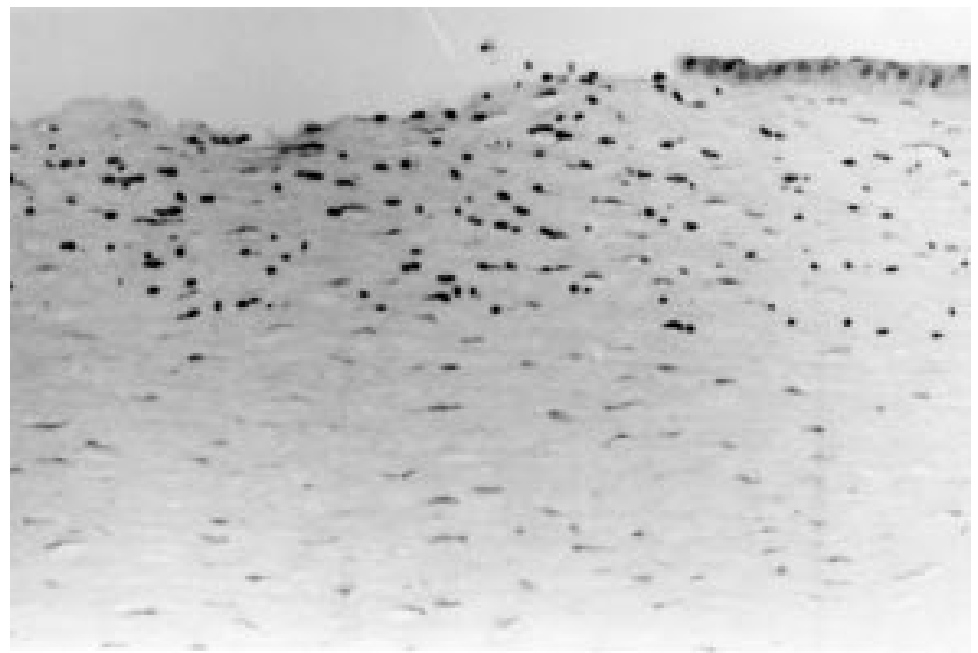

Figure 4 Haematoxylin and eosin staining showing the polymorphonuclear cells infiltrating the surface of an excimer laser ablated rabbit cornea 24 hours after excimer laser keratectomy.

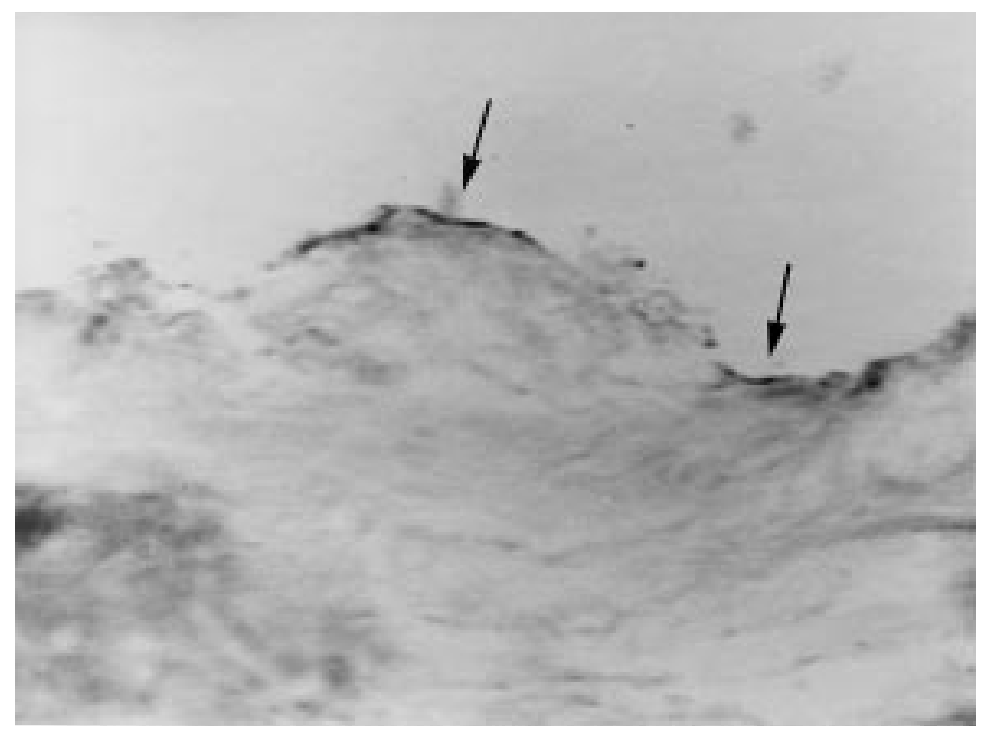

Figure 5 Photomicrograph of a corneal section where fast blue B staining shows lipid peroxide formation on the surface of the laser treated area (arrows) after 24 hours (original magnification $\times 100$ ). not show any difference in comparison with the normal corneas (data not shown).

\section{LIGHT MICROSCOPY}

Microscopic examination of corneas immediately after excimer laser ablation did not show any infiltrating inflammatory cells in the stroma (Fig 3) as well corneas from nontreated animals; however, after 24 hours, large numbers of PMNs were seen infiltrating the ablated area primarily concentrated near the treated surface (Fig 4). Fast blue B staining disclosed lipid peroxide formation on the surface of the laser treated area after 24 hours (Fig 5). Lipid peroxidation was not observed in the untreated controls.

\section{Discussion}

In this study, we have confirmed the presence and location of lipid peroxide on the ablated surface of corneas after excimer laser phototherapy. The presence of oxygen radical induced tissue damage was indirectly demonstrated by the measurement of oxidised lipids in corneal tissue by biochemical assays and was confirmed by histological examination of the laser treated tissue after fast blue B staining.

The presence of peroxidative damage in ocular tissue has been demonstrated in retinas in experimental autoimmune uveitis in rats. ${ }^{16}$ Reactive oxygen species, such as superoxide and hydrogen peroxide, are potent microbicidal agents produced by inflammatory cells such as PMNs. ${ }^{9}$ The primary species of these oxidants, $\mathrm{O}_{2}^{-}$, is produced from oxygen by stimulated PMNs and is subsequently converted to other highly reactive oxygen intermediates during the respiratory burst. These oxygen radicals may be injurious to the corneal tissues, possibly by degrading corneal collagen $^{1718}$ and by oxidising the unsaturated fatty acids present in the cell membrane in the epithelial and stromal cells. ${ }^{819}$ This type of acute injury may contribute to an increase in the incidence of corneal haze and regression of the effect of the surgery as a result of the prolonged inflammation secondary to the persistence of the inflammatory cells at the site of laser treatment. ${ }^{20}$ In this study, the oxidation of unsaturated fatty acid was documented by the measurement of conjugated dienes and ketodienes, with an increase of $87 \%$ and $198 \%$, respectively, in the laser ablated corneas.

A high influx of PMNs into rabbit corneal stroma after excimer laser therapy was recently reported. ${ }^{7}$ Our study confirms these findings and suggests that the high levels of oxidised lipids found in the irradiated corneas after 24 hours are produced by these infiltrating PMNs, since corneas removed immediately after the laser therapy did not show any oxidative damage. It is also possible that lipid peroxidation in the cornea was produced by the direct, but delayed, effect of the excimer laser on the tissue; however, recent studies show that free radicals generated during excimer laser ablation are highly reactive at room temperature and, therefore, are transient products of the photoablation event. ${ }^{21}$ 
The accumulation of PMNs close to the surface of the ablated area may be explained by the production of chemotactic agents such as arachidonic acid metabolites. ${ }^{22}$ In a recent study, however, the inhibition of prostaglandin E2 and leukotriene B4 increased the infiltration of PMNs in the cornea after excimer laser therapy. ${ }^{7}$ This finding can be explained in part by the chemotactic properties of the oxidised lipids already reported by Goto et al. ${ }^{23}$ These chemotactic agents amplify the inflammatory process, attract more PMNs to the laser ablated surface, and cause membrane lipid peroxidation at the site. This observation shows the use of topical corticosteroid immediately postoperatively may have a clinical value in humans, since it reduces the number of inflammatory cells at the site of laser treatment in rabbits. ${ }^{7}$

In conclusion, we have demonstrated the presence of oxygen radical mediated tissue damage in the form of lipid peroxidation following excimer laser keratectomy. Procedures to reduce this oxidative damage in corneas may minimise tissue damage after photorefractive surgery.

Supported in part by a grant from the Autry Foundation, Los Angeles, California, and by the National Eye Institutes/NIH core grant EY03040, Bethesda, Maryland, and an unrestricted core grant EY03040, Bethesda, Maryland, and an unrest
grant from Research to Prevent Blindness Inc, New York.

grant from Research to Prevent Blindness Inc, New York. P J McD is a William and Mary Greeve International
Research Scholar. S H is supported by a scholarship from BraResearch Scholar. S H is supported by a schol
zilian National Council for Research (CNPq).

1 Marshall J, Trokel S, Rothery S, Krueger RR. Photoablative reprofiling of the cornea using an excimer laser: photo-
refractive keratectomy. Lasers Ophthalmol 1986;1:21-48.

2 McDonald MB, Frantz JM, Klyce SD. Central photorefractve keratectomy for myopia: the blind eye study. Arch Ophthalmol 1990;108:799-808.

3 McDonnell PJ, Moreira H, Clapham TN, D'Arcy J, Munnerlyn CR. Photorefractive keratectomy for astigmatism: initial clinical results. Arch Ophthalmol 1991, 109:1370-3.

4 Sher NA, Bowers RA, Zabel RW. Clinical use of the $193 \mathrm{~nm}$ excimer laser in the treatment of corneal scars. Arch Ophthalmol 1991;109:491-8.

5 Stark WJ, Chamon W, Kamp MT, Enger CL, Rencs EV, Gottsh JD. Clinical follow-up of $193 \mathrm{~nm}$ ArF excimer laser photokeratectomy. Ophthalmology 1992;99:805-12.
6 Malley DS, Steinert RF, Puliafito CA, Dobe ET. Immunofluorescence study of corneal wound healing after excimer laser anterior keratectomy in
Ophthalmol 1990;108:1316-22.

7 Phillips AF, Szerenyi K, Campos M, Krueger RR, McDonnell PJ. Arachidonic acid metabolites after excimer laser corneal surgery. Arch Ophthalmol 1993;111:1273-8.

8 Klebanoff S. Oxygen metabolism and the toxic properties of phagocytes. Ann Intern Med 1980;93:480-9.

9 Rossi F, Bellavite P, Berton G, Grzeskowiak M, Papini E. Mechanism of production of toxic oxygen radicals by granulocytes and macrophages and their function in the inflammatory process. Pathol Res Pract 1985;180:136-42.

10 Weiss SJ, LoBuglio AF. Phagocyte-generated oxygen metabolites and cellular injury. Lab Invest 1982;47:5-18.

11 Jackson JH, Gajewski E, Schraufstatter IU, Hyslop PA, Fuciarelli AF, Cochrane CG, et al. Damage to the bases in DNA induced by stimulated human neutrophils. F Clin Invest 198;84:1644-9.

12 Goto H, Wu GS, Chen F, Kristeva M, Sevanian A, Rao NA. Lipid peroxidation in experimental uveitis: sequential studies. Curr Eye Res 1992;11:489-99.

13 Folch J, Lees M, Soloane Stanley GH. A simple method for the isolation and purification of total lipids from animal tissues. F Biol Chem 1957;226:497-509.

14 Buege JA, Aust SD. Microsomol lipid peroxidation. Methods Enzymol 1978;52:302-10.

15 Pompella A, Comporti $M$. The use of 3-hydroxy-2naphthoic acid hydrazide and fast blue $\mathrm{B}$ for the histochemical detection of lipid peroxidation in animal tissues-a microphotometric study. Histochemistry 1991; 95:255-62.

16 Rao NA. Role of oxygen free radicals in retinal damage associated with experimental uveitis. Trans Am Ophthalmol Soc 1990;88:797-851

17 Mukhopadhyay CK, Chatterjee IB. Free metal ionindependent oxidative damage of collagen. Protection by ascorbic acid. F Biol Chem 1994;269:30200-5.

18 Lonn E, Factor SM, Van HK, Wen WH, Zhao M, Dawood $\mathrm{F}$, et al. Effects of oxygen free radicals and scavengers on the cardiac extracellular collagen matrix during ischemiareperfusion. Can f Cardiol 1994;10:203-13.

19 Bazan HE, Bazan NG. Composition of phospholipids and free fatty acids and incorporation of labeled arachidonic acid in rabbit cornea. Comparison of epithelium, stroma and endothelium. Curr Eye Res 1984;3:1313-9.

20 Beuerman RW, McDonald MB, Shofner RS, Munnerlyn CR, Clapham TN, Salmeron B, et al. Quantitative histological studies of primate corneas after excimer laser photorefractive keratectomy. Arch Ophthalmol 1994;112: 1103-10.

21 Landry RJ, Pettit GH, Hahn DW, Ediger MN, Yang GC. Preliminary evidence of free radical formation during argon fluoride excimer laser irradiation of corneal tissue. Lasers Light Ophthalmol 1994;6:87-90.

22 Ford-Hutchinson AW, Bray MA, Doig MV, Shipley ME, Smith MJH. Leukotriene B, a potent chemokinetic and aggregating substance released from polymorphonuclear leukocytes. Nature 1980;286:264-5.

23 Goto H, Wu GS, Gritz DC, Atalla LR, Rao NA. Chemotactic activity of the peroxidized retinal membrane lipids in experimental autoimmune uveitis. Curr Eye Res 1991;10: 1009-14. 